$\mathrm{E}^{\mathrm{u}}$ uropa hat sein Parlament gewählt. Beklagt wird die geringe Wahlbeteiligung. Dafür mag zunächst als Erklärung herhalten, dass aus dem Parlament keine Regierung hervorgeht und dass Gesetzesvorhaben nicht von ihm selbst initiiert werden können. Man mag darauf verweisen, dass das Konstrukt EU für den Wahlbürger viel zu abgehoben sei. Doch diese Erklärungen greifen zu kurz: Hat sich irgendwo in der öffentlichen Meinung eingeprägt, welche Konzepte die einzelnen Parteien in Bezug auf Europa vertraten? Von den Kandidaten für das Parlament ging wenig Strahlkraft aus, sofern sie überhaupt bekannt waren und nicht ganz im Schatten von Personen blieben, die gar nicht zur Wahl standen. Wie sollten da die Wähler ein großes Interesse für die Wahlen zum Europaparlament entwickeln? Es war wohl eher die fehlende Bereitschaft insbesondere der großen Parteien, europapolitische Themen verständlich aufzugreifen, zuzuspitzen und personell überzeugend unter die Wähler zu bringen als die vermeintlich mangelnden Kompetenzen des Europäischen Parlaments. So gesehen ist eine Wahlbeteiligung von $42,9 \%$ gar nicht schlecht.

Kann man das Ergebnis einer ganz überwiegend von nationalen Themen geprägten Wahl europapolitisch deuten? Man kann. Das herausragende Thema, das die Menschen zurzeit bewegt, ist die Wirtschafts- und Finanzkrise. Das Wahlergebnis gibt keinerlei Anhaltspunkte dafür, dass die Wirtschaftsverfassung der EU ungeeignet sei, mit der Krise fertig zu werden. Ansonsten hätten Parteien, die mehr oder weniger dezidiert gegen die marktwirtschaftliche Verfasstheit der EU sind (Linke, Europakritiker, Nationalisten), erhebliche Stimmengewinne verbuchen müssen. Auch die Sozialdemokraten hätten dazu gewinnen müssen, die der marktwirtschaftlich ausgerichteten EU zwar

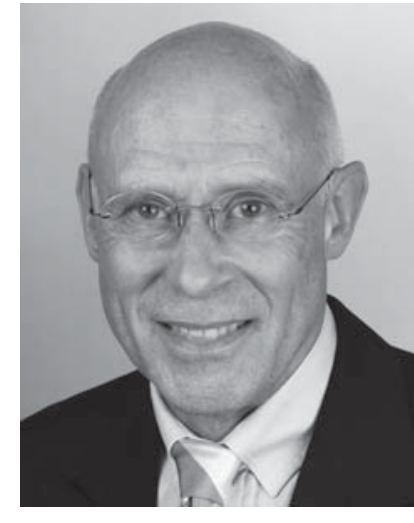

Konrad Lammers

\section{Kein Misstrauen gegenüber der EU}

nicht grundsätzlich, aber gerade jetzt in der Krise deutlich reservierter gegenüber stehen. Das Gegenteil ist der Fall. Mit den Christdemokraten, den Liberalen und den Grünen haben Parteien Stimmenanteile dazu gewonnen, die eine deutlich höhere Affinität zu dieser Ordnung erkennen lassen.

In der Tat kann gerade die Wirtschaftsverfassung der EU helfen, die Krise zu bewältigen. Die Krise ist zwar nicht von Europa ausgegangen, sie ist aber nicht minder gravierend als in den USA und deckt schonungslos Fehlentwicklungen in einzelnen Ländern und Regionen der Union auf: Die osteuropäischen Mitgliedsländer haben mit hohen Budget- und Handelsbilanzdefiziten und nachlassenden Reformen nach ihrem Beitritt über ihre Verhältnisse gelebt; die südeuropäischen Länder der Eurozone haben an Wettbewerbsfähigkeit eingebüßt, weil sie es unterlassen haben, Lohnsteigerungen und Produktivitätsentwicklungen in Einklang zu bringen; Irland und Spanien haben die spekulative Entwicklung ihrer Immobilienmärkte zugelassen. Die Liste ließe sich fortsetzen. Für diese Fehlentwicklungen sind die Mitgliedsländer verantwortlich. Die nationalen Regierungen sind deshalb auch in der Verantwortung, diese Entwicklungen zu korrigieren. Genau so sieht es auch die Wirtschaftsverfassung der EU vor. Die südeuropäischen Länder der Eurozone und die osteuropäischen Länder haben keine andere Wahl, als durch Strukturwandel und Reformen, die Produktivität zu steigern und durch ein neues Austarieren der staatlichen Einnahmen und Ausgaben, die Budgets auf eine tragfähigere Grundlage zu stellen. Die EU zwingt die Mitgliedsländer bei der Bewältigung der Krise und deren Folgen auf Pfade der wirtschaftspolitischen Vernunft. Die Unabhängigkeit der Europäischen Zentralbank gewährleistet, dass die Mitgliedsländer der Eurozone ihre Haushalte nicht über eine Inflation entschulden. Der Stabilitäts- und Wachstumspakt wird dazu anhalten, die ausgeuferten Budgetdefizite zurückzuführen. Die Wettbewerbsaufsicht wird die Mitgliedsländer bei Versuchen bremsen, Struktur erhaltende Beihilfen für einzelne Unternehmen zu gewähren.

Es mag vordergründig als Mangel erscheinen, dass die EU anders als die USA nicht ein den Wirtschaftsraum umfassendes Konjunkturpaket auf den Weg bringen kann. Aber gerade die Aufteilung der Kompetenzen zwischen EU und Mitgliedsländer, die zu großen Teilen auf dezentrale Verantwortlichkeiten ausgerichtet ist und damit angepasste Lösungen fördert, könnte ein Vorteil für eine nachhaltige Überwindung der Krise sein. Gut möglich, dass das Wahlvolk dem intuitiv vertraut. Wie gesagt, Anhaltspunkte dafür, dass diese Wahl Misstrauen gegenüber der wirtschaftlichen Verfasstheit der EU ausdrückt, gibt es nicht. Nur schade, dass der Wahlkampf nicht auf solche Themen ausgerichtet war. Kein Wunder, dass die Wahlbeteiligung so niedrig blieb.

Konrad Lammers ist Forschungsdirektor am Europa-Kolleg Hamburg und lehrt an der Universität Hamburg k-lammers@europa-kolleg-hamburg.de 